\title{
Enhanced Protein Synthesis of Heart in Adrenal- Regeneration Hypertension and Its Reduction Following Antihypertensive Treatment
}

\author{
Teruhiro Nakada, M.D., Norimasa Yamazaki, B.Sc., \\ Tohru Akiya, M.D., and Takashi Katayama, M.D.
}

\section{Summary}

After unilateral nephrectomy and bilateral adrenal enucleation at 5 weeks of age, salt-loaded rats developed hypertension (ARH) at 6 weeks. Fibrous vascular protein and in vivo incorporation of ${ }^{3} \mathrm{H}$-lysine into this protein fraction were measured at 15 weeks of age in these animals.

This study demonstrates: (1) that incorporation rates of ${ }^{3} \mathrm{H}$ lysine into cardiac collagen and elastin in ARH rats were greater than in control rats ( $p<0.001$, respectively), and (2) that administration of phenoxy-benzamine hydrochloride decreased the incorporation of tritiated lysine into cardiac collagen in ARH rats, concomitant with a reduction in blood pressure. Based on these findings, increased synthesis of cardiac collagen and elastin appears to play an important role in the development of hypertension in ARH.

\section{Additional Indexing Words:}

Aorta Collagen Elastin Phenoxybenzamine

QINCE the initial description by Skelton, ${ }^{1)}$ it is well known that unilateral $D$ nephrectomy and adrenalectomy with contralateral adrenal enucleation causes hypertensive vascular disease in salt-loaded rats. Considerable insight has been gained into the pathogenesis of adrenal-regeneration hypertension (ARH), since the development of hypertension in ARH is elicited either by bilateral adrenal enucleation, or it occurred by unilateral adrenalectomy in addition to contralateral adrenal enucleation. ${ }^{2)}$ These findings suggest that regenerated adrenals play an important role in the development of hypertension.

However, a possible role of mineralocorticoids in the development or maintenance of hypertension is controversial. ${ }^{3)-7)}$ However, some data in-

From the Department of Urology, Faculty of Medicine, Toyama Medical \& Pharmaceutical University, Toyama, Japan.

Address for reprint: Teruhiro Nakada, M.D., Department of Urology, Faculty of Medicine, Toyama Medical \& Pharmaceutical University, 2630 Sugitani, Toyama-shi 930-01, Japan.

Received for publication December 25, 1981. 
dicate that vascular protein synthesis is increased in genetically hypertensive rats and that enhanced protein biosynthesis can be diminished by antihypertensive therapy ${ }^{8)-10}$ Fractions of vascular protein, such as collagen, noncollagenous protein and elastin, are likely candidates for a vasoactive pressor factor in ARH. The amount of vascular protein available from each ARH rat is sufficient to investigate this hypothesis.

\section{Materials And Methods}

Male Wistar rats, approximately 4 weeks of age, were given Purina rat chow and $1 \% \mathrm{NaCl}$ solution ad libitum. They were maintained in quarters under controlled temperature $\left(22-24^{\circ} \mathrm{C}\right)$ and a $12 \mathrm{~h}$ light/dark cycle. All animals were acclimated to the laboratory conditions for 1 week prior to the initiation of the experiment. The rats were then divided into 3 groups: group I, was a control (C) group of 12 rats; group II, consisted of 12 bilateral adrenal-enucleated and left nephrectomized rats $(\mathrm{AE}+\mathrm{NX})$; group III, consisted of 10 bilateral adrenal-enucleated and left nephrectomized rats treated with phenoxybenzamine hydrochloride (POB) (Nikken Kagaku Co, Tokyo) $(2.5 \mathrm{mg} / \mathrm{Kg}$ body weight, s.c. twice daily) $(\mathrm{AE}+\mathrm{NX}+\mathrm{POB})$ after the age of 8 weeks. All surgical procedures were performed under pentobarbital anesthesia ( $40 \mathrm{mg} / \mathrm{Kg}$ body weight, i.p.) and adrenal enucleation was done according to the method of Ingle and Higgins. ${ }^{11}$ The systolic pressure of each conscious rat was measured periodically and just prior to the termination of the experiment with the indirect tail cuff method and recorded by an automatic blood pressure recorder model USM-105 (Ueda Instrument Co, Tokyo). After fasting overnight at the age of 15 weeks, each rat received an i.p. injection of $0.4 \mu \mathrm{Gi} / \mathrm{Gm}$ body weight of ${ }^{3} \mathrm{H}$-lysine (L-lysine $4,5-{ }^{3} \mathrm{H}$, specific activity $=78.1 \mathrm{Ci} / \mathrm{m}$ mole, New England Nuclear Corp, Boston, Mass.) and was decapitated $2 \mathrm{hrs}$ after the injection. Blood was collected from the trunk into a tube containing heparin sodium through a plastic funnel. Hearts and aortas were dissected and weighed. The left ventricle and the ascending and descending aorta, down to the level of right renal artery, were removed from each animal.

Vascular collagen was extracted by the method of Fitch et al. ${ }^{12}$ The technique employed to extract vascular non-collagenous protein was basically the same as that of Skosey et al. ${ }^{13)}$ More detailed procedures are described elsewhere. ${ }^{8)-10)}$ Vascular elastin was separated by the method of Wolinsky et al. ${ }^{14)}$ Protein concentration was assayed by the method of Lowry et al, ${ }^{151}$ with bovine serum albumin as a standard. Radiolabelled lysine incorporation into each protein fraction of the vasculature was expressed as $\mathrm{dpm} / \mathrm{mg}$ 
protein. The surplus of the experiment was operated as in the proceedings. ${ }^{9,10), 16)}$

Results are expressed as mean \pm standard error. The $p$ values shown in this study are for a 2-tailed Student's $t$ test.

\section{Results}

As shown in Fig. 1, rapid increases in blood pressure at a young age were characteristically noted after bilateral adrenal enucleation and unilateral nephrectomy in these rats consuming $1 \% \mathrm{NaCl}$ solution (group II). The average blood pressures of these rats (group II) were significantly higher $(p<$ $0.01-\mathrm{p}<0.001$ ) than those of age-matched controls (group I) between 6 weeks of age and 15 weeks of age. When hypertensive rats received POB (group III) over a period of 7 weeks, the development of hypertension was suppressed and blood pressure levels did not differ from the age-matched control rats (group I). A progressive weight gain among 3 groups of rats during the 11 weeks of experiment was apparent, and the mean body weight of groups II and III did not differ from the control group I at the termination of the experiment (Table I). As shown in Table I, the mean relative weights of heart and aorta of group II rats $(\mathrm{AE}+\mathrm{NX})$ were $22 \%$ and $73 \%$ heavier than those of group I rats $(\mathrm{C})(\mathrm{p}<0.001$, respectively). In group III rats $(\mathrm{AE}+\mathrm{NX}+\mathrm{POB})$, the

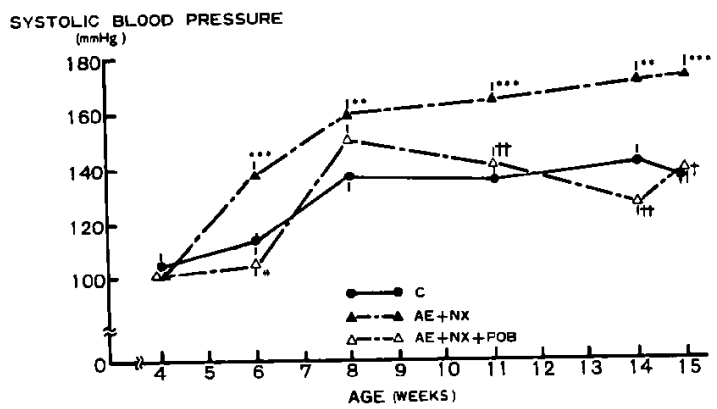

Fig. 1. The development of blood pressure in $1 \% \mathrm{NaCl}$-loaded Wistar rats during 11-week period of treatment. Groups I to III contained 10-12 rats. Rats in group I received no surgical treatment (C). Rats in group II received bilateral adrenal enucleation in addition to unilateral nephrectomy $(\mathrm{AE}+\mathrm{NX})$. Rats in group III were subjected to the same surgery as group II and were treated with $\mathrm{POB}(2.5 \mathrm{mg} / \mathrm{Kg}$, s.c. twice daily) (AE+NX+POB).

Each bar represents the SEM.

Significantly different from group I rats $(\mathrm{C})$ :

${ }^{* *} \mathrm{p}<0.01,{ }^{* * *} \mathrm{p}<0.001$.

Significantly different from group II rats $(\mathrm{AE}+\mathrm{NX})$ :

$\dagger \mathrm{p}<0.05, \uparrow \dagger \mathrm{p}<0.01,+\dagger \dagger \mathrm{p}<0.001$. 
Table I. Body and Organ Weights of Rats

\begin{tabular}{|c|c|c|c|c|}
\hline \multirow{2}{*}{ Treatment } & \multicolumn{2}{|c|}{ Body weight (Gm) } & \multicolumn{2}{|c|}{$\begin{array}{l}\text { Terminal tissue weight } \\
\text { (mg/100 Gm body weight) }\end{array}$} \\
\hline & Inital & Final & Heart & Aorta \\
\hline I. $\mathrm{C}(12)$ & $95 \pm 2$ & $345 \pm 8$ & $296 \pm 7$ & $19 \pm 2$ \\
\hline II. $\mathrm{AE}+\mathrm{NX}(12)$ & $94 \pm 1$ & $348 \pm 8$ & $362 \pm 8 * * *$ & $33 \pm 2 * * *$ \\
\hline III. $\mathrm{AE}+\mathrm{NX}+\mathrm{POB}(10)$ & $93 \pm 2$ & $331 \pm 5$ & $355 \pm 20 *$ & $30 \pm 3^{* *}$ \\
\hline
\end{tabular}

Abbreviation of each treatment as in Fig. 1.

The numbers in parentheses represent the number of animals.

Results are expressed as the mean \pm SEM.

Significantly different from group I rats $(C):{ }^{*} p<0.05, * * p<0.01, * * * p<0.001$.

Table II. Changes in Content of Vascular Protein of the Heart of Rats

\begin{tabular}{r|ccc|c}
\hline \multirow{2}{*}{ Treatment } & \multicolumn{2}{|c|}{ Content of vascular protein (mg/Gm heart) } & \multirow{2}{*}{ Collagen/Elastin } \\
\cline { 2 - 4 } & Collagen & $\begin{array}{c}\text { Non-collagenous } \\
\text { protein }\end{array}$ & Elastin & \\
\hline I. $\mathrm{C}(12)$ & $13 \pm 1$ & $59 \pm 3$ & $12 \pm 1$ & $1.4 \pm 0.2$ \\
II. $\mathrm{AE}+\mathrm{NX}(12)$ & $18 \pm 2^{*}$ & $104 \pm 3^{* * *}$ & $11 \pm 1$ & $2.5 \pm 0.3^{* *}$ \\
III. $\mathrm{AE}+\mathrm{NX}+\mathrm{POB}(10)$ & $15 \pm 1$ & $87 \pm 6^{* * *+}+$ & $11 \pm 2$ & $1.9 \pm 0.2$
\end{tabular}

The numbers in parentheses represent the number of animals.

Results are expressed as the mean \pm SEM.

Significantly different from group I rats $(\mathrm{C}):{ }^{*} \mathrm{p}<0.05,{ }^{* *} \mathrm{p}<0.01,{ }^{* * *} \mathrm{p}<0.001$.

Significantly different from group II rats $(\mathrm{AE}+\mathrm{NX}):+\mathrm{p}<0.05$.

mean relative weights of these organs were also heavier than those of group I rats $(\mathrm{C})$ to lesser extent $(\mathrm{p}<0.05, \mathrm{p}<0.01$, respectively). As shown in Table II, the amount of cardiac collagen in hypertensive group ( $\mathrm{AE}+\mathrm{NX}$ ) was $38 \%$ greater than in group $I$ rats $(G)(p<0.05)$. The content of non-collagenous cardiac protein in groups II $(\mathrm{AE}+\mathrm{NX})$ and III $(\mathrm{AE}+\mathrm{NX}+\mathrm{POB})$ was significantly greater than in group I rats $(C)(p<0.01, p<0.001$, respectively). A marked increase $(76 \%)(p<0.001)$ in content of cardiac non-collagenous protein in group II rats $(\mathrm{AE}+\mathrm{NX})$, as compared with that in group I rats (C), was reduced following POB-treatment $(\mathrm{AE}+\mathrm{NX}+\mathrm{POB}) \quad(\mathrm{p}<0.05)$. The amount of cardiac elastin was similar in all the experimental groups. The ratio of collagen/elastin in group II rats was slightly higher $(p<0.01)$ than in group I rat (Table II).

As shown in Table III, the amount of non-collagenous protein in the aorta in hypertensive rats (group II, $\mathrm{AE}+\mathrm{NX}$ ) was $43 \%$ greater than that in group I rats $(\mathrm{C})(\mathrm{p}<0.05)$. Treatment with $\mathrm{POB}$ decreased the aortic content non-collagenous protein slightly, but significantly $(p<0.05)$. The free ${ }^{3} \mathrm{H}-$-lysine radioactivity of plasma was $1016 \pm 102 \mathrm{dpm} / \mu \mathrm{l}$ in group I, $987 \pm 101$ 
Table III. Changes in Content of Vascular Protein of the Aorta of Rats

\begin{tabular}{c|cc}
\hline \multirow{2}{*}{ Treatment } & \multicolumn{2}{c}{ Content of vascular protein (mg/Gm aorta) } \\
\cline { 2 - 3 } & Collagen & Non-collagenous protein \\
\hline I. C (12) & $35 \pm 2$ & $7 \pm 1$ \\
II. AE+NX (12) & $34 \pm 2$ & $10 \pm 1 *$ \\
III. AE+NX+POB (10) & $32 \pm 4$ & $7 \pm 1 \dagger$
\end{tabular}

The numbers in parentheses represent the number of animals.

Results are expressed as the mean \pm SEM.

Significantly different from group I rats $(C):{ }^{*} p<0.05$.

Significantly different from group II rats $(\mathrm{AE}+\mathrm{NX}): \dagger \mathrm{p}<0.05$.

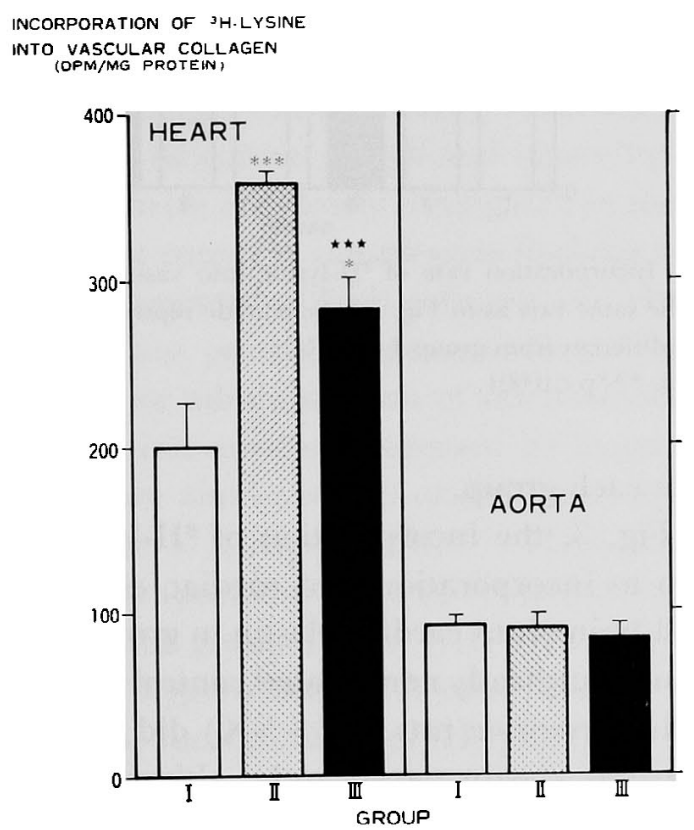

Fig. 2. Incorporation rate of ${ }^{3} \mathrm{H}$-lysine into vascular collagen (dpm/mg protein) of 15 -week-old rats consuming $1 \% \mathrm{NaCl}$ solution. Rats from groups I to III received various treatments from 4 to 15 weeks of age, as described in detail in the text. Each column with a vertical bar represents the mean $+\mathrm{SE}$. Significantly different from group I rats (C):

${ }^{*} \mathrm{p}<0.05, * * * \mathrm{p}<0.001$.

Significantly different from group II rats $(\mathrm{AE}+\mathrm{NX})$ :

$\star \star \star \mathrm{p}<0.001$.

$\mathrm{dpm} / \mu \mathrm{l}$ in group II, and $1040 \pm 82 \mathrm{dpm} / \mu 1$ in group III, respectively, and did not differ among the experimental groups. Fig. 2 illustrates the incorporation of ${ }^{3} \mathrm{H}$-lysine into cardiac and aortic collagen in all groups. The increased incorporation of ${ }^{3} \mathrm{H}$-lysine into cardiac collagen in hypertensive rats in group II $(\mathrm{AE}+\mathrm{NX}, \mathrm{p}<0.001)$ was reduced by the administration of POB (group III, $\mathrm{AE}+\mathrm{NX}+\mathrm{POB}, \mathrm{p}<0.001)$. The incorporation of ${ }^{3} \mathrm{H}$-lysine into aortic col- 


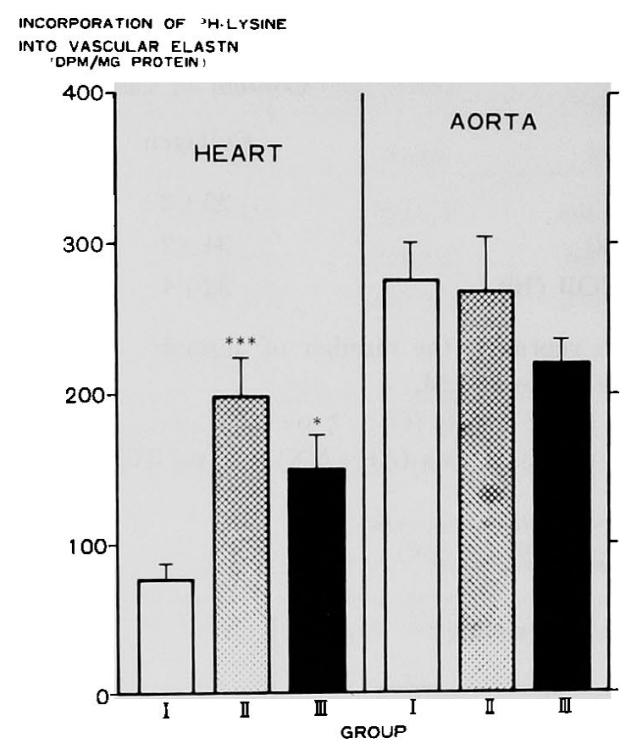

Fig. 3. Incorporation rate of ${ }^{9} \mathrm{H}$-lysine into vascular elastin $(\mathrm{dpm} / \mathrm{mg}$ protein) of the same rats as in Fig. 1. Schematic representation as in Fig. 2. Significantly different from group I rats $(\mathrm{C})$ :

${ }^{*} \mathrm{p}<0.05,{ }^{* * *} \mathrm{p}<0.001$.

lagen was similar in each group.

As shown in Fig. 3, the incorporation of ${ }^{3} \mathrm{H}$-lysine into cardiac elastin was similar pattern to incorporation into cardiac collagen. The incorporation rate of tritiated lysine into cardiac elastin in group II rats $(\mathrm{AE}+\mathrm{NX})$ was 2.6 -fold greater than in surgically non-treated control rats (group I) $(\mathrm{p}<0.001)$. $\mathrm{POB}$-treatment of hypertensive rats $(\mathrm{AE}+\mathrm{NX})$ did not reduce the lysine incorporation into cardiac elastin significantly, although there was a trend toward lower lysine incorporation into cardiac elastin (group III, AE+NX+ POB). There is a considerable variation in the susceptibility of individual groups to incorporation of ${ }^{3} \mathrm{H}$-lysine into aortic elastin. However, there was no significant difference in the ${ }^{3} \mathrm{H}$-lysine incorporation into aortic elastin between group I and other groups (Fig. 3).

\section{Discussion}

The literature is replete with investigations of vascular protein in spontaneously hypertensive rats (SHR), assuming that increased vascular protein synthesis, especially in small arteries may be a major cause of the pathogenesis of genetic hypertension. ${ }^{\text {)-10) }}$ Recent published reports, including our earlier studies, noted little appreciable difference in the incorporation of ${ }^{3} \mathrm{H}$-lysine 
into collagen or elastin in large vessels of normotensive rats and SHR rats. ${ }^{81,10)}$ This is the first study to examine the relationship of vascular protein to ARH. The results of this study demonstrate some important variables. For example, the increased incorporation of ${ }^{3} \mathrm{H}$-lysine into collagen or elastin in hearts of hypertensive rats $(\mathrm{AE}+\mathrm{NX})$ was decreased by antihypertensive treatment with $\mathrm{POB}$ (Figs. 2 and 3). However, several factors make it premature to directly compare results in SHR and ARH rats. Young rats (8 weeks of age) were used in earlier SHR studies, ${ }^{8), 10)}$ and adult rats were utilized in the present experiments. Moreover, etiological factors contributing to blood pressure elevation in ARH may not be identical with those in SHR.

Collagen, the most abundant fibrous protein in mammals, is stabilized by the establishment of covalent cross-links and is relatively stiff. Elastin, a major component of elastic fibers, contains many cross-links and is capable of stretching to several times its normal length and returning to its original size. Both connective tissue proteins are closely conjugated in the walls of aorta and heart. ${ }^{17)}$ One of the most common conspicuous findings in hypertensive vascular lesions is increased amounts of both collagen and elastin. The proportion of both connective tissue proteins appears to be altered by the prolonged duration of hypertension or administration of sex hormones. Values of vascular collagen/elastin are increased or decreased by hypertensive or hypotensive treatment, ${ }^{7), 18)}$ and are also increased or decreased by the administration of testosterone or estradiol-17 $\beta$, respectively. ${ }^{16)}$ Thus, the increased amount of collagen, enhanced incorporation rates of ${ }^{3} \mathrm{H}$-lysine and the high ratio of collagen/elastin in hearts of group II rats $(\mathrm{AE}+\mathrm{NX}$, Table II), may be attributed to the effects of hypertension. Another unique finding in the present experiment is that the incorporation of ${ }^{3} \mathrm{H}$-lysine into the non-collagenous protein of hearts and aortas was identical in all experimental groups (data not shown), but that the average amount of cardiac non-collagenous protein in group II rats $(\mathrm{AE}+\mathrm{NX})$ was 1.8 -fold greater than that in group I rats $(\mathrm{C})$ (Table II). In addition, this elevated level of non-collagenous protein in hypertensive rats (group II) was diminished by antihypertensive treatment (Table II). The mechanism which underlies this phenomenon is difficult to understand, but it seems probable that the increased synthesis of vascular noncollagenous protein in the early hypertensive period may have led to vasoconstriction, developing high blood pressure under the strong influence of increased synthesis of vascular collagen and elastin. Since the extent of compensation varies, a great amount of cardiac non-collagenous protein may partially contribute to blood pressure elevation, even though the tritiated lysine incorporation into this protein fraction is almost similar among experimental groups. The derivation of this protein fraction is a challenge for future in- 
quiry. The accumulation of cardiac non-collagenous protein in hypertensive rats (group II, $\mathrm{AE}+\mathrm{NX}$ ) may be due, in part, to an inhibition of degradative enzymes, a decrease in the turnover or the formation of precursor of this protein fraction. In this experiment, all animals were sacrificed after hypertension was established. Thus, at present, the vascular protein fraction changes that precede the onset of hypertension are unknown.

\section{ACKNOWLEDGMENTS}

This study was supported by a grant for research from the Ministry of Health and Welfare of Japan (557366) and, in part, by a grant from Mitsui Seimei Kosei Jigyodan Foundation. The authors wish to thank Dr. Walter Lovenberg, Section on Biochemical Pharmacology, Hypertension-Endocrine Branch, National Heart, Lung and Blood Institute, National Institutes of Health, Bethesda, Maryland 20205, and Dr. Yukio Yamori, Department of Pathology, Shimane Medical University, Shimane, Japan, for their help and advice through the investigation. We thank Miss A. Ueno for typing the manuscript.

\section{REFERENGES}

1. Skelton FR: Development of hypertension and cardiovascular renal lesions during adrenalregeneration in the rat. Pro Soc Exp Biol Med 90: 342, 1955

2. Oelsner T, Skelton FR: Complementary role of adrenal cortex and salt in adrenal-regeneration hypertension. Physiol 200: 749, 1961

3. Bergon L, Gallant S, Brownie AG: Cholesterol sidechain cleavage activity and levels of highspin cytochrome P-45 in adrenal-regeneration hypertension (ARH). Endocrinol 94: 336, 1974

4. Bergon L, Brownie AC: Adrenal mitochondrial and serum corticosteroid studies in rats resistant to adrenal-regeneration hypertension (ARH). Endocrinol 99: 1080, 1976

5. Hauger-klevene JH, Vecsei P: Deoxycorticosterone measured a radioimmunoassay in vivo in rats undergoing adrenal regeneration. Clin Sci Med 51: 299s, 1976

6. Gomez-Sanchez C, Holland OB, Murry BA: Mineralocorticoid radioreceptor assay: application to adrenal-regeneration hypertension. Life Sci 21 : 989, 1977

7. Ooshima A, Fuller GC, Cardinale GJ, Spector S, Udenfriend S: Increased collagen synthesis in blood vessels of hypertensive rats and its reversal by antihypertensive agents. Proc Nat Acad Sci USA 71 : 3019, 1974

8. Yamori Y, Nakada T, Lovenberg W: Effect of antihypertensive therapy on lysine incorporation into vascular protein of the spontaneously hypertensive rat. Europ J Pharmacol 38: 349, 1976

9. Yamori Y: Vascular protein metabolism in the pathogenesis of hypertension. Jap Cric J 4: 879, 1976

10. Nakada $T$, Lovenberg $W$ : Lysine incorporation in vessels of spontaneously hypertensive rats: effects of adrenergic drugs. Europ J Pharmacol 48: 87, 1978

11. Ingle DJ, Higgins GM: Regeneration of the adrenal gland following enucleation. Am J Med Sci 196: 232, 1938

12. Fitch SM, Harkness MLR, Harkness RDH: Extraction of collagen from tissues. Nature (London) 176: 163, 1955

13. Skosey JL, Zak R, Martin AF, Aschenprenner V, Rabinowitz M: Biochemical correlates of cardiac hypertrophy. V. Labeling of collagen, myosin, and nuclear DNA during experimental myocardial hypertrophy in the rat. Circulat Res 31 : 145, 1972 
14. Wolinsky $\mathrm{H}$ : Response of rat aortic media to hypertension. Morphological and chemical studies. Circulat Res 26: 507, 1970

15. Lowry OH, Rosenbrough NJ, Farr AL, Randall RJ: Protein measurement with the folin phenol reagent. J Biol Chem 193: 265, 1951

16. Nakada T, Katayama T, Shimazaki J: Suppression of ${ }^{3} \mathbf{H}-l y s i n e$ incorporation into the vascular non-collagenous protein in rats treated with estradiol-17 $\beta$. Europ J Pharmacol 59: 31, 1979

17. Stryer L: Connective-tissue proteins: collagen and elastin. in Biochemistry, ed by Stryer L, WH Freemand and Co, San Francisco, p 206, 1975

18. Fischer GM, Swain ML: Effect of sex hormones on blood pressure and vascular connective tissue in castrated and noncastrated male rats. Am J Physiol 232: H617, 1977 